\title{
Lone Atrial Flutter in Children and Adolescents: Is It Really “Lone”?
}

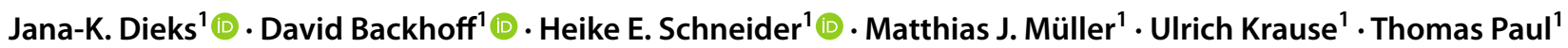

Received: 7 May 2020 / Accepted: 30 October 2020 / Published online: 9 November 2020

(c) The Author(s) 2020

\begin{abstract}
Atrial flutter (AFL) in children and adolescents beyond the neonatal period in the absence of any underlying myocardial disease ("lone AFL") is rare and data is limited. Our study aims to present clinical and electrophysiological data of presumed "lone AFL" in pediatric patients and discuss the role of endomyocardial biopsy (EMB) and further follow-up. Since July 2005, eight consecutive patients at a median age of 12.7 (range 10.4-16.7) years presenting with presumed "lone AFL" after negative non-invasive diagnostic work-up had electrophysiological study (EPS) and induction of cavotricuspid isthmus (CTI) conduction block by radiofrequency (RF) current application. In 6/8 patients EMB could be taken. Induction of CTI conduction block was achieved in all patients. Histopathological examination of EMB from the right ventricular septum exhibited myocarditis or cardiomyopathy in 4/6 patients, respectively. During follow-up, 4/8 patients had recurrent arrhythmia (AFL $n=2$, wide QRS complex tachycardia $n=1$, monomorphic premature ventricular contractions $n=1$ ) after the ablation procedure. 3/4 patients with recurrent arrhythmia had pathological EMB results. The remaining patient with recurrent arrhythmia had a negative EMB but was diagnosed with Brugada syndrome during further follow-up. Taking together results of EMB and further clinical course, only $3 / 8$ patients finally turned out to have true "lone AFL". Our study demonstrates that true "lone AFL" in children and adolescents is rare. EMB and clinical course revealed an underlying cardiac pathology in the majority of the individuals studied. EMB was very helpful in order to timely establish the diagnosis of myocarditis or cardiomyopathy.
\end{abstract}

Keywords Atrial flutter $\cdot$ Catheter ablation $\cdot$ Endomyocardial biopsy $\cdot$ Radiofrequency current $\cdot$ Pediatrics $\cdot$ Adolescents

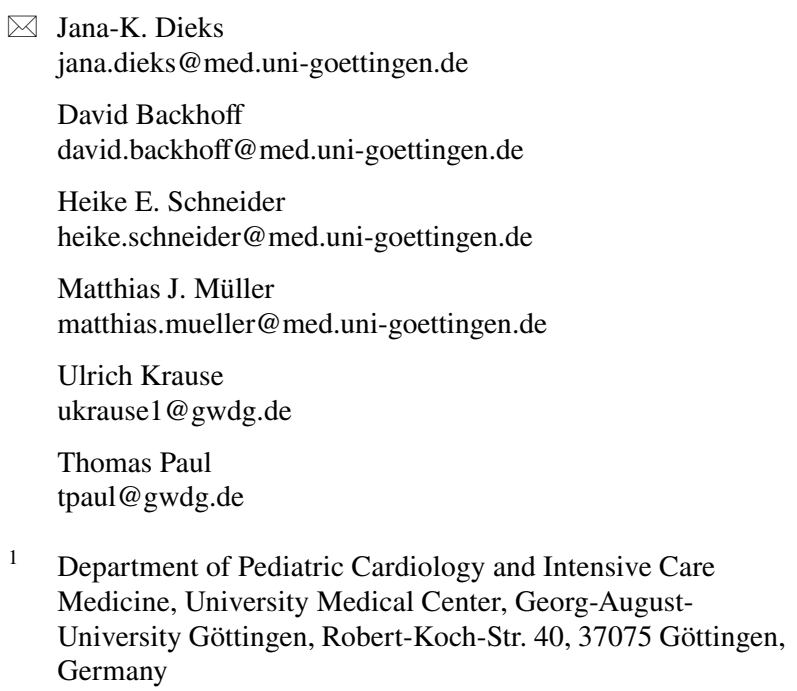

1 Department of Pediatric Cardiology and Intensive Care Medicine, University Medical Center, Georg-AugustUniversity Göttingen, Robert-Koch-Str. 40, 37075 Göttingen, Germany

\section{Introduction}

In pediatric patients, atrial flutter (AFL) without any obvious cardiac abnormatility ("lone AFL") is rare and most frequently occurs in the neonatal period [1]. Beyond this age, AFL primarily occurs in the presence of congenital heart disease (CHD) [1-3], in patients with accessory atrioventricular (AV) pathways [4], in myocarditis [5, 6] and in patients with various types of cardiomyopathy [7]. In a sentinel study from 1985 on AFL in the young with limited diagnostic methods available at that time, less then $10 \%$ of the patients had an "otherwise" normal heart ("lone AFL") [8].

In adults, incidence of AFL increases with age [9]. Adult patients either have a history of ischaemic heart disease or prior cardiac surgery [10]. A familial risk has been described particularly in patients diagnosed before 50 years of age [11], and a genetic mutation predisposing for AFL has been identified [12].

In neonates and infants with AFL and a structurally normal heart, AFL is thought to be benign. After conversion into sinus rhythm, long-term antiarrthythmic therapy is not 
recommended as recurrences are very rare $[1,13]$. In children and adolescents, depending on clinical presentation and efficacy of antiarrhythmic medication, electrophysiological study (EPS) and catheter ablation is the treatment of choice allowing for substrate specific treatment of AFL [14].

As actual data on AFL in pediatric patients beyond the neonatal period without any obvious underlying myocardial disease is limited, our study aims to present the clinical features and management of presumed "lone AFL" in this group of patients focussing on the value of endomyocardial biopsy (EMB) and the further clinical course.

\section{Patients and Methods}

\section{Patients}

Inclusion critera: All children and adolescents $(<18$ years of age) referred to our tertiary pediatric electrophysiology center for EPS and catheter ablation of AFL in the absence of overt cardiac disease between July 2005 and January 2018 were studied. AFL was the only arrhythmia documented prior to EPS. Before admission to our institution, electrocardiogram (ECG) during sinus rhythm and transthoracic echocardiogram had been judged to be normal. After admission to our institution, all patients underwent a standardized non-invasive work-up (see below). Overt absence of cardiac disease was defined as follows: normal ECG [15], normal transthoracic echocardiogram according to standard criteria [16] (normal anatomy, cardiac dimensions appropriate for body weight, normal left ventricular fractional shortening/ ejection fraction, normal right ventricular function and no pericardial effusion), and exclusion of any systemic disease with potential cardiac involvement. All patients had EPS and intended induction of cavotricuspid isthmus (CTI) block by RF application (see below).

\section{Non-invasive Work-Up}

A detailed medical history including family history was taken. Age of AFL onset, clinical symptoms, number and duration of AFL episodes, and previous therapy were documented. A 12-lead surface ECG and a 24-h Holter were obtained prior to EPS. AFL on surface ECG was characterized and defined as typical (counterclockwise) or atypical (clockwise) according to standard ECG criteria [17]. All patients underwent detailed two-dimensional transthoracic echocardiographic evaluation to rule out structural cardiac abnormalities. Since 2009, contrast-enhanced cardiac magnetic resonance imaging (CMR) was performed including cine imaging, $\mathrm{T} 1$ - and $\mathrm{T} 2$-weighted imaging, phase contrast flow measurements, volumetry, tissue characterization of the myocardium and late enhancement in three patients.

\section{Electrophysiological Study and Catheter Ablation}

Written informed consent was obtained from all patients, their parent(s) and/or legal guardian(s) prior to EPS. All antiarrhythmic medication was withdrawn at least five half-lives prior to EPS if applicable. Following complete cardiac catheterization including hemodynamic assessment (oxymetry, manometry, and calculations of cardiac index and pulmonary vascular resistance) and right and left ventricular angiographies as well as selective coronary angiography, EPS, endocardial mapping and radiofrequency ablation (RFA) were performed according to standard protocols [18] using non-fluroscopic mapping systems $[19,20]$. CTI block was induced by pointby-point RF applications using RF generator power settings of $30-50 \mathrm{~W}$ and a target temperature of $45^{\circ} \mathrm{C}$ at the $4 \mathrm{~mm}$ tip of the irrigated 7F ablation catheter (Marinr MCXL, Medtronic, Minneapolis, MN, USA or CoolPath Duo, St. Jude Medical, St. Paul, MN, USA) for a maximum of $45 \mathrm{~s}$ per lesion. Primary endpoint of catheter ablation was termination of AFL during RF application where applicable, proof of bidirectional CTI conduction block according to standard criteria and non-inducibility of AFL after RFA. Bidirectional CTI conduction block was defined as an increase of the trans-isthmus conduction time by at least $50 \%$ in both directions when compared to pre-RF state [21]. All patients had programmed atrial stimulation including incremental and single, double and triple extrastimulus testing with a minimum cycle length of 200 ms prior to RFA \pm following RFA. Before performing the post-ablation study, there was a waiting time of $30 \mathrm{~min}$. Programmed ventricular stimulation \pm isoprenalin provocation was performed in three patients prior to RFA.

\section{Endomyocardial Biopsy}

Upon completion of EPS and RFA, five EMB from the right ventricular septum were taken in all patients in whom written informed consent could be obtained $(n=6)$ using a 7F Mullins Fast-Cath ${ }^{\text {TM }}$ Sheeth (St. Jude Medical) and a 5.5F biopsy forceps (Cordis, Milpitas, CA, USA). Three EMB were fixed in buffered $4 \%$ formaldehyde solution (Carl Roth, Karlsruhe, Germany), and two EMB were stored in RNAlater ${ }^{\circledR}$ stabilization solution (Thermo Fisher Scientific, Waltham, MA USA) for evaluation of viral genoma. EMB were sent to the Department of Molecular Pathology, University Hospital Tübingen, Germany, for examination. Standard work-up [22] included immunohistopathology for signs of acute or persistent infection or inflammation, eosinophilia, primary or secondary cardiomyopathy and storage disease. Polymerase chain reaction 
examinations were performed from biopsy samples and blood to rule out myocardial or systemic viral infection.

\section{Follow-Up}

After hospital discharge regular follow-up visits were scheduled at the referring pediatric cardiologist or at the outpatient clinic of our institution.

\section{Statistical Analysis}

Data was handled with Microsoft Excel (version 2016, Redmond, WA, USA). Continuous variables are expressed as median (range) or mean \pm standard deviation, categorical variables as percentages.

\section{Results}

\section{Patients}

A total of eight pediatric and adolescent patients meeting the inclusion criteria underwent diagnostic work-up and catheter ablation for presumed "lone AFL". One patient was female. Median age at onset of AFL had been 12.7 (range 10.1-15.4) years. All patients had experienced symptoms during AFL (Table 1). 6/8 patients (75\%) had suffered from sustained ( $\geq 30 \mathrm{~s}$ ) AFL episodes. Of these patients, $2 / 6$ patients had syncope related to the arrhythmia. Additional symptoms included palpitations, chest pain, dizziness and dyspnea. Prior to EPS, $3 / 8$ patients had needed cardioversion for sustained AFL. The remaining 2/8 patients had non-sustained $(<30 \mathrm{~s})$ AFL as documented on Holter monitor. 1/8 patients with high arrhythmia burden had been treated with antiarrhythmic medication. None of the patients had had a previous EPS.

\section{Non-invasive Findings}

Median age at diagnostic work-up in our institution was 13.6 (10.4-16.7) years, body weight was $54(33-100) \mathrm{kg}$. Median interval between AFL onset and EPS was 10 (1-38) months.

\section{Electrocardiogram}

ECG prior to EPS showed incomplete right bundle branch block in $2 / 8$ patients (25\%). All patients had conduction times and electrical forces within age-appropriate limits. None of them had evidence for repolarization abnormalities (Table 1).

In all patients, counterclockwise AFL with a median cycle length of 236 (190-280) ms and variable AV conduction (1:1 to $4: 1)$ had been documented.

\section{Holter Monitoring}

24-h Holter monitoring revealed normal sinus rhythm in $6 / 8$ patients $(75 \%)$. Of the remaining two patients, one was in sustained AFL and the other patient had two episodes of non-sustained AFL documented.

\section{Transthoracic Echocardiography}

Echocardiographic work-up revealed normal results in all patients.

\section{Cardiac Magnetic Resonance Imaging}

3/8 patients had CMR with normal results in all of them.

\section{Invasive Findings}

\section{Hemodynamic Studies}

Complete invasive hemodynamics and angiographies for evaluation was available in all patients. Hemodynamics were completely normal in $6 / 8$ patients $(75 \%$; Table 1$)$. The remaining two patients had an elevated left ventricular end diastolic pressure (LVEDP of 13 and $16 \mathrm{mmHg}$, respectively). On angiography, one patient exhibited increased trabecularization of both ventricles and a slightly reduced left ventricular function with an ejection fraction (EF) of $51 \%$ (reference values in male patients: normal $52-72 \%$, slightly reduced $41-51 \%$, reduced $30-40 \%$, and markedly reduced $<30 \%$ ) [23].

\section{Electrophysiological Study: Characterization of Atrial Flutter and Associated Arrhythmias}

AFL was inducible by programmed stimulation in $6 / 8$ patients (75\%). CTI-dependent AFL was verified by positive entrainment within the CTI in all of them. During EP assessment, spontaneous degeneration of AFL into atrial fibrillation was observed in 3/8 patients. In the remaining two patients (25\%), AFL was not inducible during EPS.

A median of 15 (9-42) RF applications with a median total burning time of 10.3 (4.7-24.6) min was required for induction of CTI conduction block. At repeat programmed atrial stimulation after RFA, one patient had inducible AV nodal reentrant tachycardia. RFA of the slow conducting pathway was performed during the same procedure. Three patients had unifocal $(n=2)$ or multifocal atrial tachycardia $(n=1)$ which were not targeted during the intial procedure because these tachycardias could not reproducibly be induced or were only short-lasting.

Median total procedure time was 192 (142-230) min, median total fluoroscopy time was $12.3(2.7-27.2) \mathrm{min}$ 


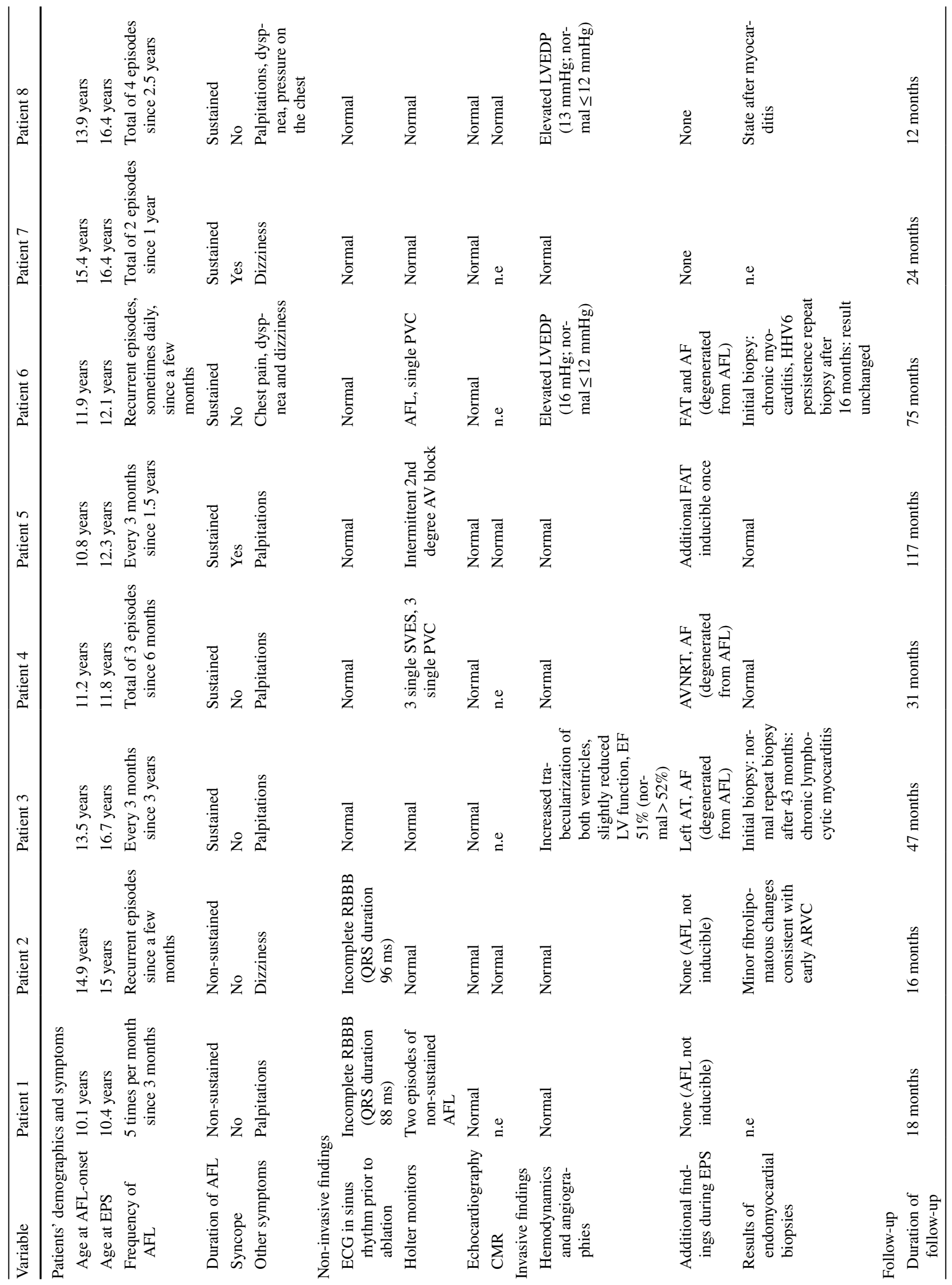




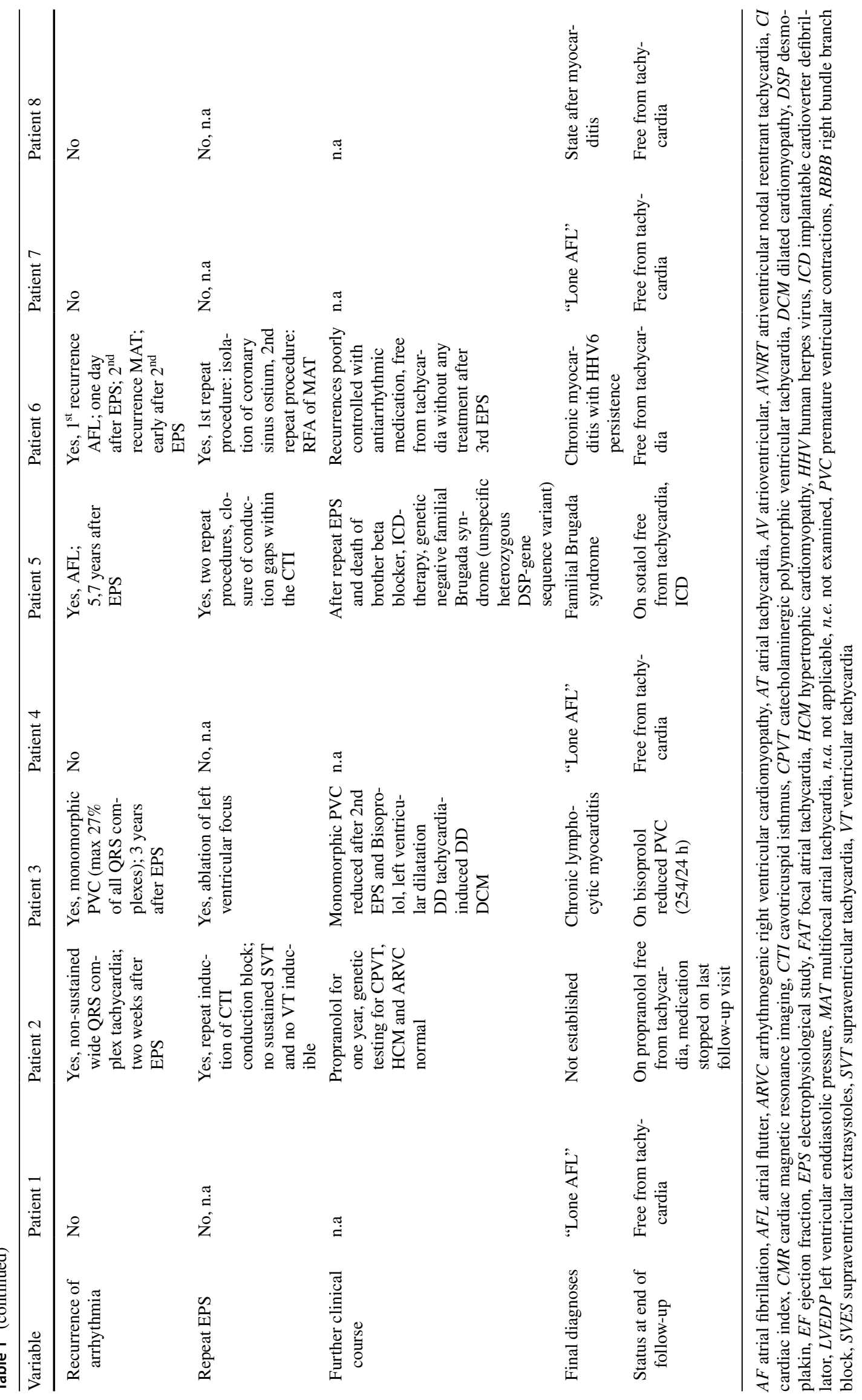


including hemodynamic assessement and angiography as well as obtaining EMB.

\section{Acute Success and Complications}

In the two patients lacking induction of AFL during EPS, induction of bidirectional CTI conduction block was empirically performed. Termination of AFL during AFL was achieved in the remaining six individuals. All eight patients had a successful ablation procedure as defined above. No procedure-related complications were observed.

\section{Endomyocardial Biopsy and Histopathological Findings}

EMB could be taken in $6 / 8$ patients. In $3 / 6$ patients $(50 \%)$, EMB revealed pathologic findings. One patient had evidence of chronic myocarditis with HHV6 persistence, another patient had persisting myocarditis, and one patient showed minor fibrolipomatous changes consistent with an early state of arrhythmogenic right ventricular cardiomyopathy (ARVC). In the remaining three patients EMB were considered normal.

During further clinical course $2 / 6$ patients had repeat EMB taken. In the patient with chronic myocarditis, repeat analysis showed unchanged results. In one patient with initially normal EMB results, there was evidence for chronic lymphocytic myocarditis during follow-up.

Taking initial and repeat EMB together, 4/6 patients (66.6\%) had pathological results. Detailed information on results of EMB is provided in the Table 1.

\section{Follow-Up}

During a mean follow-up of $43 \pm 31$ months, cardiac arrhythmia events defined as any event of supraventricular or ventricular tachyarrhythmia were registered in $4 / 8$ patients early (within 4 weeks; $n=3$ ) or late (68 months; $n=1$ ) after the procedure, respectively. Recurrent AFL was documented in 2/4 patients, broad QRS complex tachycardia in one, and monomorphic premature ventricular contractions (PVC) in another patient. Of these four patients, three had pathological EMB results, the remaining patient was diagnosed with familial Brugada syndrome six years after AFL ablation.

All four patients with cardiac arrhythmia events during follow-up had repeat EP procedures. Two individuals had repeat successful induction of CTI conduction block after four weeks and 68 months, respectively. One patient had RFA of a left-ventricular ectopic focus after 43 months. The remaining patient needed two EPS/ablation procedures after five and 21 months for multiple focal atrial tachycardia while complete CTI conduction block was proven.

On their last follow-up visit, $6 / 8$ patients $(75 \%)$ were without any evidence of tachycardia without any specific treatment. One patient still had PVC (250/day) four years after the initial RFA while taking bisoprolol $5 \mathrm{mg}$ bid. In the last patient diagnosed with Brugada syndrome, control of breakthrough atrial tachycardias was achieved with sotalol $80 \mathrm{mg}$ bid.

The patient whose EMB had shown minor fibrolipomatous changes consistent with early ARVC developed non-sustained wide QRS complex tachycardia early after EPS. Repeat EPS did not show a substrate for this recurrent arrhythmia. Repeat CTI conduction block was induced to close a residual conduction gap. Consecutively, the patient was started on propranolol. He had negative genetic testing for catecholaminergic polymorphic ventricular tachycardia, hypertrophic cardiomyopathy and ARVC. After 16 months of follow-up, he was free from tachycardia while on antiarrhythmic medication.

At the conclusion of follow-up of our patient cohort, only 3/8 patients met the definition of true "lone AFL".

\section{Discussion}

Over the last 14 years, a limited number of patients had been referred to our tertiary pediatric electrophysiology center for EPS and ablation of presumed "lone AFL" suggesting a very low incidence of the tachycardia in this age group. One main finding of the present study is, that "lone AFL" might actually not be "lone" at all in this age group, as after negative non-invasive workup, previously un-diagnosed underlying pathologies were present in 4/6 biopsy specimen (66.6\%). Moreover, in one patient with recurrent arrhythmia and negative EMB, familial Brugada syndrome was diagnosed later-on.

\section{Epidemiology of "Lone Atrial Flutter"}

Data regarding the prevalence of AFL in patients with a structurally normal heart is limited. In an initial study from $1985,6.3 \%$ of 380 young AFL patients aged one to 25 years had a normal heart defined as no repaired, palliated or unoperated congenital heart disease, no cardiomyopathy, no rheumatic heart disease and no other lesions. However, in the early 80ies of the last century, diagnosis of a "normal heart without evidence of cardiomyopathy" had been established by physical examination, chest X-ray, occasionally 2D-echocardiography (35.2\% of all patients) and mainly by cardiac catheterization (67.4\% of all patients). EMB and MRI had not been performed at all [8].

During the period of our study, a total of 870 pediatric patients underwent catheter ablation for SVT or atrial tachycardia at our institution. Taking this group of patients as denominator, incidence of presumed "lone AFL" was $0.9 \%$, while incidence of "true" lone AFL was $0.3 \%$. It is of note 
that in five of our eight patients initially assessed to have "lone AFL", EMB and the mid-term clinical course revealed significant pathological findings including additional supraventricular or ventricular tachycardias, cardiomyopathy, channelopathy or myocarditis $(n=3)$. For myocarditis, the mechanism of arrhythmogenesis has been described to be the interaction of host (inflammation) and viral (altered cellular signaling) factors that can induce ion electrophysiological and structural remodeling leading to triggered and reentrant arrhythmia [24]. Especially for acute myocarditis, several outcome predictors have been described focusing on arrhythmia burden and reduced ventricular function mainly during the first hospitalization. Here, in the early phase, arrhythmias were related with a worse outcome [6]. However, after discharge from hospital, a majority of patients did not require continued antiarrhythmic treatment and recurrences are rare [25]. In our study, of the three patients with myocarditis, one required repeat EPS and additional longterm antiarrhythmic treatment and one required two repeat EPS. All three patients were free from rachycardia at the end of follow-up.

\section{Underlying Cardiac Pathology and Impact of Endomyocardial Biopsy}

In a significant number of our study patients, transient or persistent underlying cardiac pathologies were identified. EMB substantially contributed to diagnosis and individual management. However, taking the probability of false negative biopsy results due to a sampling error and that permission for EMB was denied in two patients, the number of patients with true "lone AFL" may have even been lower than assessed. However, those two patients who had no EMB taken were free from cardiac arrhythmia events during a follow-up of 18 and 24 months, respectively.

EMB was safe in our group of patients and contributed significantly to establishing the final diagnosis. Severe complications in children, however, have been reported [26].

\section{General Considerations}

In the present study, acute success of AFL ablation by induction of CTI conduction block was achieved in all our patients during initial EPS which is consistent with the high efficacy $>90 \%$ as reported for AFL ablation in adults [27-30]. In adults, half of atrial arrhythmia recurrences following AFL ablation were documented early within the first month after EPS [29] with atrial fibrillation being a significant cofinding with an incidence of approximately 30\% [27-29]. In our study group, AFL recurrences predominantly developed within the first weeks after ablation raising the question whether these events have to be judged as failures instead of early recurrences.
Only a limited number of our study patients had CMR studies. Interestingly, in our experience, CMR did not add any significant information to the diagnostic work-up. The number of patients, however, was extremely limited. No final conclusion on the impact of cardiac MRI in this setting can be drawn.

It also needs to be considered to include further genetic testing in the early standard work-up of presumed lone AFL in children and adolescents as it is already routine in many centers around the world. This recommendation is underlined by our finding, that at least one of our study patients was found to have a familial cardiomyopathy.

\section{Conclusions}

In a significant number of patients with presumed lone AFL, EMB revealed evidence for underlying cardiac disease. Therefore, detailed non-invasive and invasive diagnostic work-up including EMB is recommended in young patients with presumed "lone AFL" allowing disease-specific treatment. The role of CMR and genetic testing in this setting remained undetermined but its use is strongly recommended in order to obtain relevant data in the future.

\section{Limitations of the Study}

Limitations of our study include the retrospective design and the single-center approach. Only a small number of patients fulfilled criteria of presumed lone AFL. As data in the literature is sparse, we have the feeling that our results on this entity are of major impact and may serve as guidance for systematic work-up of future young patients with presumed "lone AFL". As the role of CMR is still undefined, cost-effectiveness also needs to be discussed.

Funding Open Access funding enabled and organized by Projekt DEAL. This research did not receive any specific grant from funding agencies in the public, commercial, or not-for-profit sectors.

\section{Compliance with Ethical Standards}

Conflict of interest The authors declare that they have no conflicts of interest.

Ethical Approval This retrospective chart review study involving human participants was in accordance with the ethical standards of the local institutional review board, the national research committee and with the 1964 Helsinki Declaration and its later amendments or comparable ethical standards. 
Open Access This article is licensed under a Creative Commons Attribution 4.0 International License, which permits use, sharing, adaptation, distribution and reproduction in any medium or format, as long as you give appropriate credit to the original author(s) and the source, provide a link to the Creative Commons licence, and indicate if changes were made. The images or other third party material in this article are included in the article's Creative Commons licence, unless indicated otherwise in a credit line to the material. If material is not included in the article's Creative Commons licence and your intended use is not permitted by statutory regulation or exceeds the permitted use, you will need to obtain permission directly from the copyright holder. To view a copy of this licence, visit http://creativecommons.org/licenses/by/4.0/.

\section{References}

1. Brugada J, Blom N, Sarquella-Brugada G, Blomstrom-Lundqvist C, Deanfield J, Janousek J, Abrams D, Bauersfeld U, Brugada R, Drago F, de Groot N, Happonen JM, Hebe J, Yen Ho S, Marijon E, Paul T, Pfammatter JP, Rosenthal E, A European Heart Rhythm Association for European P, Congenital C (2013) Pharmacological and non-pharmacological therapy for arrhythmias in the pediatric population: EHRA and AEPC-Arrhythmia Working Group joint consensus statement. Europace 15:1337-1382

2. Johnson JN, Marquardt ML, Ackerman MJ, Asirvatham SJ, Reeder GS, Cabalka AK, Cetta F, Hagler DJ (2011) Electrocardiographic changes and arrhythmias following percutaneous atrial septal defect and patent foramen ovale device closure. Catheter Cardiovasc Interv 78:254-261

3. Wu MH, Lu CW, Chen HC, Chiu SN, Kao FY, Huang SK (2015) Arrhythmic burdens in patients with tetralogy of Fallot: a national database study. Heart Rhythm 12:604-609

4. Harahsheh A, Du W, Singh H, Karpawich PP (2008) Risk factors for atrioventricular tachycardia degenerating to atrial flutter/fibrillation in the young with Wolff-Parkinson-White. Pacing Clin Electrophysiol 31:1307-1312

5. Sankar J, Khalil S, Jeeva Sankar M, Kumar D, Dubey N (2011) Short-term outcomes of acute fulminant myocarditis in children. Pediatr Cardiol 32:885-890

6. Anderson BR, Silver ES, Richmond ME, Liberman L (2014) Usefulness of arrhythmias as predictors of death and resource utilization in children with myocarditis. Am J Cardiol 114:1400-1405

7. Price JF, Jeewa A, Denfield SW (2016) Clinical characteristics and treatment of cardiomyopathies in children. Curr Cardiol Rev 12:85-98

8. Garson A Jr, Bink-Boelkens M, Hesslein PS, Hordof AJ, Keane JF, Neches WH, Porter CJ (1985) Atrial flutter in the young: a collaborative study of 380 cases. J Am Coll Cardiol 6:871-878

9. Granada J, Uribe W, Chyou PH, Maassen K, Vierkant R, Smith PN, Hayes J, Eaker E, Vidaillet H (2000) Incidence and predictors of atrial flutter in the general population. J Am Coll Cardiol $36: 2242-2246$

10. Dallaglio PD, Anguera I, Jimenez-Candil J, Peinado R, Garcia-Seara J, Arcocha MF, Macias R, Herreros B, Quesada A, Hernandez-Madrid A, Alvarez M, Di Marco A, Filgueiras D, Matia R, Cequier A, Sabate X (2015) Impact of previous cardiac surgery on long-term outcome of cavotricuspid isthmusdependent atrial flutter ablation. Europace 18:873-880

11. Zoller B, Ohlsson H, Sundquist J, Sundquist K (2013) High familial risk of atrial fibrillation/atrial flutter in multiplex families: a nationwide family study in Sweden. J Am Heart Assoc 2:e003384
12. Roberts JD, Hsu JC, Aouizerat BE, Pullinger CR, Malloy MJ, Kane JP, Olgin JE, Marcus GM (2014) Impact of a 4q25 genetic variant in atrial flutter and on the risk of atrial fibrillation after cavotricuspid isthmus ablation. J Cardiovasc Electrophysiol 25:271-277

13. Texter KM, Kertesz NJ, Friedman RA, Fenrich AL Jr (2006) Atrial flutter in infants. J Am Coll Cardiol 48:1040-1046

14. Philip Saul J, Kanter RJ, Writing C, Abrams D, Asirvatham S, Bar-Cohen Y, Blaufox AD, Cannon B, Clark J, Dick M, Freter A, Kertesz NJ, Kirsh JA, Kugler J, LaPage M, McGowan FX, Miyake CY, Nathan A, Papagiannis J, Paul T, Pflaumer A, Skanes AC, Stevenson WG, Von Bergen N, Zimmerman F (2016) PACES/HRS expert consensus statement on the use of catheter ablation in children and patients with congenital heart disease: developed in partnership with the Pediatric and Congenital Electrophysiology Society (PACES) and the Heart Rhythm Society (HRS). Endorsed by the governing bodies of PACES, HRS, the American Academy of Pediatrics (AAP), the American Heart Association (AHA), and the Association for European Pediatric and Congenital Cardiology (AEPC). Heart Rhythm 13:e251-289

15. Davignon A, Rautaharju P, Boisselle E, Soumis F, Mégélas M, Choquette A (1979/1980) Normal ECG standards for infants and children. Pediatr Cardiol 1:123-131

16. Lai WW, Geva T, Shirali GS, Frommelt PC, Humes RA, Brook MM, Pignatelli RH, Rychik J, Task Force of the Pediatric Council of the American Society of E, Pediatric Council of the American Society of E (2006) Guidelines and standards for performance of a pediatric echocardiogram: a report from the Task Force of the Pediatric Council of the American Society of Echocardiography. J Am Soc Echocardiogr 19:1413-1430

17. Rostock T, Konrad T, Sonnenschein S, Mollnau H, Ocete BQ, Bock K, Spittler R, Huber C, Theis C (2015) Surface ECG characteristics of right and left atrial flutter. Herzschrittmachertherapie \& Elektrophysiologie 26:208-213

18. Gillette PC, Garson A (1999) Clinical pediatric arrhythmias, 2nd edn. Saunders, Philadelphia, W.B

19. Klehs S, Schneider HE, Backhoff D, Paul T, Krause U (2017) Radiofrequency catheter ablation of atrial tachycardias in congenital heart disease: results with special reference to complexity of underlying anatomy. Circ Arrhyth Electrophysiol 10:5451

20. Bollmann A, Hilbert S, John S, Kosiuk J, Hindricks G (2016) Initial experience with ultra high-density mapping of human right atria. J Cardiovasc Electrophysiol 27:154-160

21. Tai CT, Haque A, Lin YK, Tsao HM, Ding YA, Chang MS, Chen SA (2002) Double potential interval and transisthmus conduction time for prediction of cavotricuspid isthmus block after ablation of typical atrial flutter. J Interv Cardiac Electrophysiol 7:77-82

22. Kindermann I, Barth C, Mahfoud F, Ukena C, Lenski M, Yilmaz A, Klingel K, Kandolf R, Sechtem U, Cooper LT, Bohm M (2012) Update on myocarditis. J Am Coll Cardiol 59:779-792

23. Lang RM, Badano LP, Mor-Avi V, Afilalo J, Armstrong A, Ernande L, Flachskampf FA, Foster E, Goldstein SA, Kuznetsova T, Lancellotti P, Muraru D, Picard MH, Rietzschel ER, Rudski L, Spencer KT, Tsang W, Voigt JU (2015) Recommendations for cardiac chamber quantification by echocardiography in adults: an update from the American Society of Echocardiography and the European Association of Cardiovascular Imaging. Eur Heart J Cardiovasc Imaging 16:233-270

24. Tse G, Yeo JM, Chan YW, Lai ET, Yan BP (2016) What is the arrhythmic substrate in viral myocarditis? Insights from clinical and animal studies. Front Physiol 7:308

25. Miyake CY, Teele SA, Chen L, Motonaga KS, Dubin AM, Balasubramanian S, Balise RR, Rosenthal DN, Alexander ME, Walsh EP, Mah DY (2014) In-hospital arrhythmia development 
and outcomes in pediatric patients with acute myocarditis. Am J Cardiol 113:535-540

26. Pophal SG, Sigfusson G, Booth KL, Bacanu SA, Webber SA, Ettedgui JA, Neches WH, Park SC (1999) Complications of endomyocardial biopsy in children. J Am Coll Cardiol 34:2105-2110

27. Calkins H, Canby R, Weiss R, Taylor G, Wells P, Chinitz L, Milstein S, Compton S, Oleson K, Sherfesee L, Onufer J, Group WAII (2004) Results of catheter ablation of typical atrial flutter. Am J Cardiol 94:437-442

28. Brembilla-Perrot B, Sellal JM, Olivier A, Manenti V, Villemin T, Beurrier D, De Chillou C, Lamiral Z, Girerd N (2015) Risk and outcome after ablation of isthmus-dependent atrial flutter in elderly patients. PLoS ONE 10:e0127672
29. Cosio FG, Arribas F, Lopez-Gil M, Gonzalez HD (1996) Atrial flutter mapping and ablation II. Radiofrequency ablation of atrial flutter circuits. Pacing Clin Electrophysiol 19:965-975

30. Feld G, Wharton M, Plumb V, Daoud E, Friehling T, Epstein L, Investigators E-XCAS (2004) Radiofrequency catheter ablation of type 1 atrial flutter using large-tip 8- or 10-mm electrode catheters and a high-output radiofrequency energy generator: results of a multicenter safety and efficacy study. J Am Coll Cardiol 43:1466-1472

Publisher's Note Springer Nature remains neutral with regard to jurisdictional claims in published maps and institutional affiliations. 